\title{
Increase of infectious syphilis among heterosexuals in Amsterdam: its relationship to drug use and prostitution
}

\author{
J A R van den Hoek, M M D van der Linden, R A Coutinho
}

\begin{abstract}
Since 1986, an increase in heterosexually acquired syphilis cases has been seen in Amsterdam. The proportion of syphilis patients who reported using hard drugs, increased from $7 \%$ in 1985 to $23 \%$ in 1988 , which was mainly due to increased numbers of addicted prostitute women with syphilis.
\end{abstract}

Since 1984, reported rates of syphilis in many areas of the United States have greatly increased. ${ }^{12}$ A national increase was noted in the last half of $1986 .{ }^{3}$ The increase occurred exclusively among heterosexuals, while among homo- and bisexual men a marked decrease was seen, reflecting the change of lifestyle in that group under the influence of AIDS. ${ }^{1-3}$ Studies conducted in Connecticut and Philadelphia identified a relationship among those heterosexuals who acquired syphilis between prostitution and drug use. ${ }^{4}$ In Amsterdam (The Netherlands), which has a population of approximately 700,000 a similar increase in heterosexually acquired syphilis has been seen since 1987, which we report here.

\section{Methods and results}

About $80^{\circ}$ " of the reported cases of infectious syphilis reported in Amsterdam are diagnosed in the two STD clinics of the Municipal Health Service. Of all these patients background data are registered like sexual preference, prostitution and addiction to hard drugs.

If we look at the different subgroups of infectious syphilis patients (primary, secondary and early latent syphilis of less than 1 year's duration based on history, previous negative serological tests, absence of clinical symptoms or signs and positive treponemal serology), diagnosed in these clinics (see table), a decline is seen in the numbers of cases among

Municipal Health Service, PO Box 20244, 1000 HE Amsterdam, The Netherlands

JAR van den Hoek

MMD van der Linden

RA Coutinho
Table Number of early syphilis patients diagnosed at the STD clinics in Amsterdam (Municipal Health Service), 1985-1988

\begin{tabular}{lrrrr}
\hline & 1985 & 1986 & 1987 & 1988 \\
\hline Heterosexual men & 16 & 23 & 53 & 62 \\
Homo/bisexual men & 114 & 69 & 33 & 13 \\
Prostitute women & 11 & 6 & 16 & 23 \\
$\begin{array}{l}\text { Non-prostitute women } \\
\text { Risk group unknown }\end{array}$ & 1 & 9 & 10 & 12 \\
Total & 150 & 107 & 112 & 111 \\
$\begin{array}{l}\text { Number of patients } \\
\quad \text { using hard drugs) }\end{array}$ & 11 & 9 & 22 & 26 \\
\hline
\end{tabular}

homo- and bisexual men (114 in 1985 to 13 in 1988). However, among heterosexual men the number of cases is increasing (1985: 16;1988: 62). In women a similar trend is seen (1985: 19 and 1988: 35) which was mainly due to an increase of syphilis in prostitute women (11 and 23 respectively). The proportion of syphilis patients who reported the use of hard drugs, increased from $7^{\circ}{ }_{0}$ in 1985 to $23^{\circ}{ }_{0}$ in 1988 . This increase is mainly due to the increased numbers of addicted prostitutes with syphilis, as in 198820 of the 23 prostitutes with this disease $\left(87^{\circ}{ }_{0}\right)$ were said to use hard drugs, compared with 4 out of the $11\left(36^{\circ}{ }_{0}\right)$ in 1985 . Heterosexual male syphilis patients did not show an increase in recorded drug use, nor did the homo-bisexual syphilis patients.

\section{Comment}

The consequences of this change in the epidemiology of syphilis for Amsterdam may be great, as there are approximately 500 addicted prostitutes in this town of whom around $30^{\circ}{ }^{\circ}$, are infected with the human immunodeficiency virus among whom the prevalence of other STD is also very high. ${ }^{50}$

This group may therefore play an important role in the HIV-transmission both towards their customers and their private partners (apart from their role in the spread of other STD) especially since studies have suggested that sexually transmitted diseases that cause genital ulcers, such as syphilis, facilitate the transmission of HIV.$^{7-4}$ Most major cities in Europe as well as in the United States have to do with the phenomenon of prostitution by addicted women. 
Special STD programmes for addicted prostitutes (which have existed in Amsterdam since $1979^{6}$ ) have to be organised or intensified to try to prevent HIV transmission.

Address for reprints: JAR van den Hoek, Municipal Health Service, PO Box 20244, 1000 HE Amsterdam, The Netherlands

1 Anonymous. Increase in primary and secondary syphilisUnited States. $M M W R$ 1987;25:393-7.

2 Leads from the MMWR. Continuing increase in infectious syphilis-United States. JAMA 1988;259:995-7.

3 Syphilis and congenital syphilis-United States, 1985-1988. MMWR 1988;32:486-90.

4 Anonymous. Relationship of syphilis to drug use and prostitu-
tion-Connecticut and Philadelphia, Pennsylvania. $M M W R$ 1988;49:755-64.

5 Hoek JAR van den, Coutinho RA, Haastrecht HJA van, Zadelhoff AW van, Goudsmit J. Prevalence and risk factors of HIV infections among drug users and drug using prostitutes in Amsterdam. AIDS 1988;2:55-60.

6 Hoek JAR van den, Haastrecht HJA van, Scheeringa-Troost B, Goudsmit J, Coutinho RA. HIV infections and sexually transmitted diseases among addicted prostitutes in Amsterdam; the potential of heterosexual transmission. Genitourin Med 1989;65:146-50.

7 Greenblatt RM, Cukehart SA, Plummer FA, et al. Genital ulceration as a risk factor for human immunodeficiency virus infection. AIDS 1988;2:47-50.

8 Holmberg SD, Stewart JA, Gerber AR, et al. Prior herpes simplex virus type 2 infection as a risk factor for HIV infections. JAMA 1988;259:1048-50.

9 Cameron DW, D'Costa LJ, Ndinya-Achola JO, Piot $P$, Plummer FA. Incidence and risk factors for female to male transmission of HIV (abstract). IV International Conference on AIDS, Book 1. Stockholm, June 12-16, 1988:275.

Accepted for publication 8 November 1989 